PAPER • OPEN ACCESS

\title{
Bioimpedance and bone fracture detection: A state of the art
}

To cite this article: A H Dell'Osa et al 2019 J. Phys.: Conf. Ser. 1272012010

View the article online for updates and enhancements.

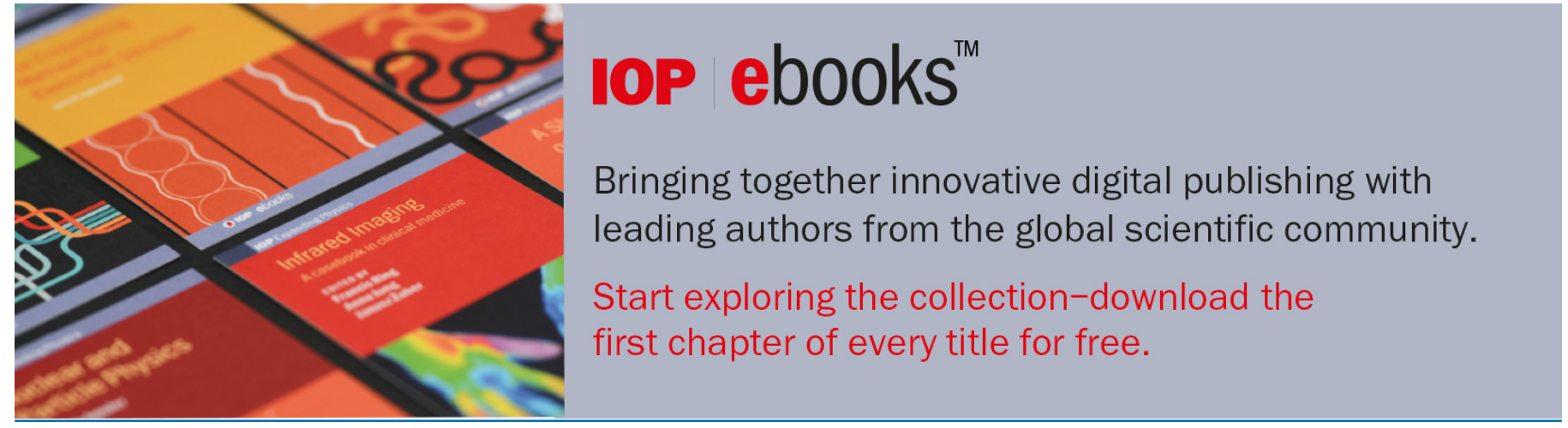

This content was downloaded from IP address 181.118 .101 .214 on $06 / 04 / 2020$ at 18:20 


\title{
Bioimpedance and bone fracture detection: A state of the art
}

\author{
A H Dell'Osa ${ }^{1,2,3}$, C J Felice ${ }^{2,3}$ and F Simini ${ }^{4}$ \\ ${ }^{1}$ Instituto de Desarrollo Económico e Innovación, Universidad Nacional de Tierra del \\ Fuego, Fuegia Basket 271, Ushuaia, Tierra del Fuego, Argentina \\ ${ }^{2}$ Consejo Nacional de Investigaciones Científicas y Técnicas (CONICET), Argentina. \\ ${ }^{3}$ Laboratorio de Medios e Interfases, Instituto Superior de Investigaciones Biológicas, \\ CONICET, Tucumán, Argentina \\ ${ }^{4}$ Núcleo de Ingeniería Biomédica, Facultad de Ingeniería, Universidad de la \\ República, Montevideo, Uruguay
}

\section{E-mail: ahdellosa@untdf.edu.ar}

\begin{abstract}
Bioimpedance measurements are used increasingly in health applications because bioelectric parameters have been associated with anatomical and physiological properties, thus enabling to distinguish medical conditions. For bone fracture diagnostics, nevertheless, there is no established non-invasive method. Ex vivo studies and In vivo bioimpedance procedures, both invasive and non-invasive, on mammalians long bones are associated with promising results. In this work, out of a total of 568 papers, we reviewd 59 articles that mention long bone integrity by electric properties, be it Bioimpedance Analysis, Electrical Impedance Spectroscopy or Electrical Impedance Tomography. The papers are described in three sections, "Ex vivo measurements", "In vivo invasive measurements" and "In vivo non-invasive measurements". This review allows to establish the basics to planning the development of new technology to detect bone fracture via bioimpedance measurements.
\end{abstract}

\section{Introduction}

Bioimpedance is defined as impedance measurement of a biological system [1]. As impedance is the magnitude opposing current flow in an electrical circuit when voltage is applied to it, all parameters are governed by Ohm's law [2]. Different from "resistance" which opposes direct current flow, "impedance" results from the application of alternating tension or current. There is thus one "impedance" for every frequency of the stimulating current waveform.

Bioimpedance measurements stem from Ohm's Law applied to the resulting signal (either voltage or current) in a biological system when energy is applied in the form of a stimulating signal (either current or voltage respectively). If the injected signal is a current, the measurement will be voltage potential and vice versa. Electrodes are used as interfaces between the external measuring unit and the biological system, both to apply and to measure the resulting magnitude. The injected signal has a known amplitude and frequency and the resulting amplitude and phase measurements define the bioimpedance in terms of "modulus" and "phase". This can be expressed as a complex number with a real part known as resistance and an imaginary part for reactance. Resistance and reactance depend of resistivity and permittivity, respectively, and their geometrical size. Resistivity and permittivity are electrical properties of materials and media. In biological systems, the reactance only can be zero or 
negative (capacitive behavior) not positive (inductive behavior). In electrical systems, this is different, the reactance can have capacitive or inductive behavior or zero (purely resistive) [1,3].

We are reviewing in the present paper three techniques as applied to bone fractures, namely Bioimpedance Analysis (BIA), Electrical Impedance Spectroscopy (EIS) as well as in Electrical Impedance Tomography (EIT).

BIA is a method which gives one single biompedance measurement (including modulus and phase), since the stimulating alternating signal is a simple sine wave at a given frequency. EIS yields a set of bioimpedance measurements, called a "spectrum" (hence its denomination), since a set of signals (all of the same amplitude but at different frequencies) is successively injected. Sometimes EIS is described as a signal spectrum being applied since the same signal amplitude is assigned to a succession of either increasing or decreasing frequencies, within the spectrum "band width" [3]. In both BIA and EIS the measurements can be done using either bipolar, tripolar o tetrapolar electrode configurations, i.e. using two, three or four electrodes [1]. For EIT, the spatial resolution of the reconstructed images requires more electrodes or measurement points, usually chosen as a power of two, starting at 16 electrodes. EIT systems typically inject current at two electrodes and measure signals at the remaining electrodes, two by two, following one of a number of possible sequences and configurations [3-5]. In contrast to BIA and EIS, EIT gives a vector of bioimpedance values each associated with its position on a bidimensional mapping. There is a qualitative difference separating BIA and EIS on one side and EIT on the other since the latter is the result of intense mathematical calculations to "create" a slice of bioimpedance values of the body under examination. EIT is usually performed on mixed media volume, such as the thorax, where water and air have very different electrical properties. EIT estimates internal bioimpedance values from external measurements and reconstructs an internal image. This mathematical operation as known as "to solve an inverse problem" because the original electrical properties of each internal point is unknown and only the external consequences of its existence are measurable on the outside, i.e. on the skin of the patient. In much the same way the EKG is the result of skin measurements of internal electrical activity of the heart. The cardiologist in his/her mind reconstructs the cardiovascular function by interpreting EKG signals[6, 7], EIT is used to build imaging estimates of a region confined by the electrodes. Both human anatomical and dynamic function parameters -such as pulmonary ventilation- can be quantified by EIT [3]. Long bone integrity deduced from EIT is an unusual topic of research, since most of EIT applictions deal with chest exploration and regional ventilation.

Since the discovery of $\mathrm{X}$ rays, bone fractures are diagnosed by visual interpretation of $\mathrm{X}$ ray projections on either a film (XX Century) or electronic arrays (digital radiography, XXI Century) $[8,9]$. Despite the present trend to reduce the $\mathrm{X}$ ray energy involved, there is always an accumulative effect of the ionizing radiation, which increases the statistical likeliness of cellular nucleus damage leading to unwanted mutations [8]. Moreover, $\mathrm{X}$ ray equipment is usually large and expensive, even in its mobile versions for Emergency Departments. To overcome these inconveniences -ionizing radiation, size and cost- a few research groups is considering bioimpedance to describe the result of trauma on bone structure.

The present review describes bioimpedance measurements to detect long bones fractures. Research papers on the characterization of different tissues are not included, and neither bone growth electrostimulation.

\section{Measurements Methods}

The review selected all papers written in English from 1928 to 2018 with the key words bioimpedance, bone, fracture, detection, spectroscopy, analysis, monitoring, electrical impedance tomography, bioresistivy in different combination. The databases used been the digital library of Ministerio de Ciencia y Tecnología de la Republica Argentina (which has access to ACM Digital Library, ACP Scitation, American Chemical Society, American Physics Society, Annual reviews, BioMed Central, IEEE Xplore Digital Library, IOP Science, JSTOR, Knovel, Lyell Collection, Nature Journals, SAGE Premier, SciELO, Science Magazine, Science Direct, Sistema Nacional de 
Respositorios Digitales, SpringerLink, SpringerOpen, Wiley Online Library and Wiley Open Access) and Google Scholar $\odot$. The results of these searches were a total of 568 of which only 58 deal with mammalian long bones (femur, tibia, peroneum, humerus, radius and cubitus) AND describe some method or measurement of electrical properties tending ultimately to describe structural bone integrity.

The papers are described in the following three sections, "Ex vivo measurements" reporting 30 papers, "In vivo invasive measurements" 8 papers and "In vivo non-invasive measurements" with 14 papers. All papers described refer to one,- or more- of the BIA, EIS or EIT methods implemented.

\subsection{Ex vivo measurements}

Hemingway [10] and Burger et al. [11,12] are the first authors (1943 and 1961) to describe the electrical properties of bone tissue. Geddes and Baker later write an interdisciplinary compendium with both physiologists and engineers input [13]. The compendium describes several tissues, bioimpedance-wise, showing special interest and deeper analysis for bone tissue. Bone tissue has a large bioelectric variability due to its morphological diversity, evidenced by differences between long bones and compact bones [13]. BIA was used with fixed frequencies of $1.25 \mathrm{MHz}$ and $10 \mathrm{MHz}$.

A very important contribution was made by C. Gabriel in a series of papers which included conductivity and permittivity of biological tissues of several species (human, bovine, sheep, porcine, among others) using EIS in three different electrode configurations [14-16]. Bioimpedance is given at different frequencies and measured with different electronic equipment: from $10 \mathrm{~Hz}$ to $10 \mathrm{MHz}$ with HP4182A, from $300 \mathrm{kHz}$ to $3 \mathrm{GHz}$ with $\mathrm{HP} 8720$ and from $130 \mathrm{MHz}$ to $20 \mathrm{GHz}$ with HP8753. The same author had previously developed compensation models to reduce measurement errors due to coaxial cables, and published calibration curves [17].

Bone structure anisotropy was first addressed when bioimpedance was measured in different directions (axial, radial and longitudinal) of long bones [18-21]. Mercato et al. [18] measured bone samples applying $500 \mathrm{mV}$ to bipolar electrodes at three frequencies: $100 \mathrm{~Hz}, 10 \mathrm{k} \mathrm{Hz}$ and $1 \mathrm{MHz}$, using an LCR Meter (HP4192A). Casas and Sevostianov [19] perform a tetrapolar measurements with an HP4338B. Saha et al. [20,21] report bipolar measurements in three directions taken with an LCR meter (HP4275A) at frequencies of $10 \mathrm{kHz}, 100 \mathrm{kHz}$ and $1 \mathrm{MHz}$. Another set of measurements was limited to axial and longitudinal directions at $120 \mathrm{~Hz}, 1 \mathrm{kHz}, 20 \mathrm{kHz}, 40 \mathrm{kHz}, 200 \mathrm{kHz}, 400 \mathrm{kHz}, 2$ $\mathrm{MHz}, 4 \mathrm{MHz}$ and $10 \mathrm{MHz}$. These results are shown as EIS in Figure 1.
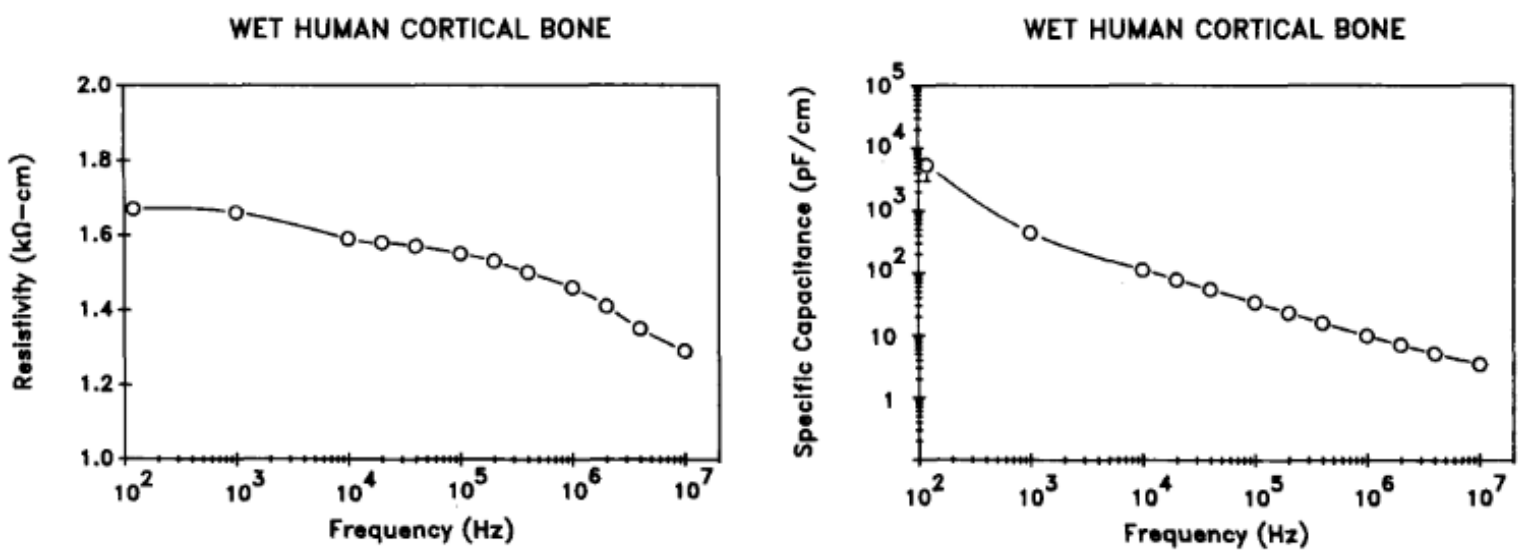

Figure 1. Electrical Impedance Spectroscopy. A. Average resistivity for the axial direction as a function of frequency. B. Average specific capacitance for the axial direction as a function of frequency [21].

Among electro-stimulation reports, there is an interest in biompedance estimations as a means to distinguish osteogenesis stages [22-27]. These papers give BIA and EIS experimental measurements, using function generators, ohmmeters and frequency counters. Since there are no bioimpedance figures for the same bone, intact and broken, these papers are not included in the present review. 
Some authors [28-32] have studied the mechanical properties of the bone, specifically its integrity and porosity. Macromolecular analysis describes the correlation of bone electrical properties with protein structure [33]. This was done using strain gauges and spectroscopy to highlight deformation.

Since the measurements are made 'ex-vivo', bones are exposed to external pollution, some papers $[23,34,35]$ have addressed measurement inaccuracies secondary to ambient conditions.

Electrical properties of bones (conductivity and permittivity) have been estimated to model them with a passive element circuit [36]. For safety reasons [37], measurement only above $20 \mathrm{kHz}$ are taken $(20 \mathrm{kHz}, 50 \mathrm{kHz}$ and $100 \mathrm{kHz}$ ) with an impedance analyzer (Agilent 4294A).

In buco-maxilo-facial surgery, ex-vivo bioimpedance measurements help to verify the correct osteo-integration of implants. EIS measurements are taken on two metallic implants into the bone [38] in the range of $10 \mathrm{~Hz}$ to $65 \mathrm{kHz}$ with an impedance analyzer (Solartron 1250) and an electrochemical interface (Solartron 1286). For this application the injected signal is a pure sinusoid of either $10 \mathrm{mV}$ or $100 \mathrm{mV}$.

Despite the fact that the papers described so far include elements that can be used to distinguish bone lesions, only one author [39] gives ex vivo figures of the same bone, intact and fractured [39]. A current of $400 \mu \mathrm{A}$ at $50 \mathrm{kHz}$ is injected in a buffalo tibia using two $\mathrm{Ag} / \mathrm{AgCl}$ electrodes affixed on the bone surface to measure three conditions: : intact, semi-fractured and fractured. There are differences between the three states, as recorded by a BioPAC system. Figure 2 shows the bone bioimpedance variations as it is partially, then completely broken.

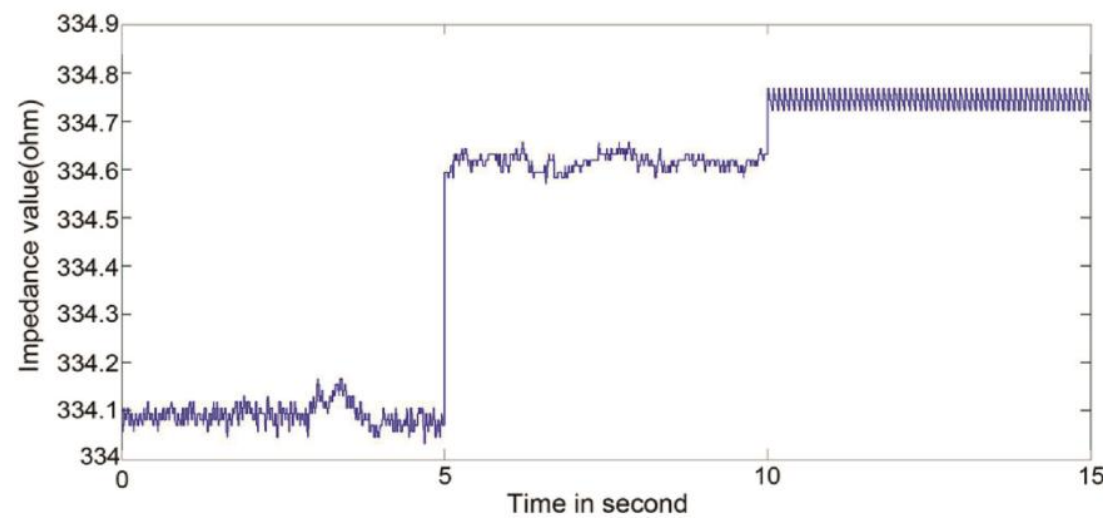

Figure 2. Buffalo tibial bioimpedance from intact to broken condition. From 334.1 ohm for intact, $\mathrm{Z}$ increases to 334.7 for fractured bone. After Khan et al.[39].

Lin et al. [40,41] published cadaveric bone electrical properties before fracture and during the reduction process [40,41]. Every phase of healing is measured by EIS in bipolar mode with embedded electrodes and Keysight Technologies E4980AL-100 Precision LCR device - Sinus tension of 100 $\mathrm{mV}$ at frequencies of $20 \mathrm{~Hz}$ to $1 \mathrm{MHz}$.

\subsection{In vivo measurements}

2.2.1. Animal In-vivo Measurements. In vivo measurements of bone lesions in animals are carried out after fracturing it under controlled conditions. The electrical parameters are then monitored in parallel with $\mathrm{X}$ ray imaging. Both the bone lesion and invasive electrode positioning are done under anaesthesia.

Most papers reporting in-vivo procedures include the electrical stimulation to foster bone morphogenesis [42-45]. It was not until 1982 that an in vivo paper reports bone electrical stimulation to record its bioimpedance [46]. Rinaldi and Goodrich verify with five embedded femur electrodes in rabbits what had been published until then. Figure 3 shows electrode positioning and bioimpedance measurement layout. Frequency was $20 \mathrm{~Hz}$ to $7000 \mathrm{~Hz}$ and applied voltage 0.1 volts to 1.2 volts with 
General Radio Oscillator model 1316 (variable voltage), Keithley 168 Auto-ranging digital multimeter and a Dynascan electronic multimeter Model 290.

Yoshida et al. [47] publish BIA at constant frequency $(2.0 \pm 0.4 \mathrm{~Hz})$ and current $(30 \pm 6 \mu \mathrm{A})$ of rabbit bones surgically implanted external nails. Their aim was to record bioimpedance during the healing process after osteotomy. Different bioimpedance values were found for every bone union phase.

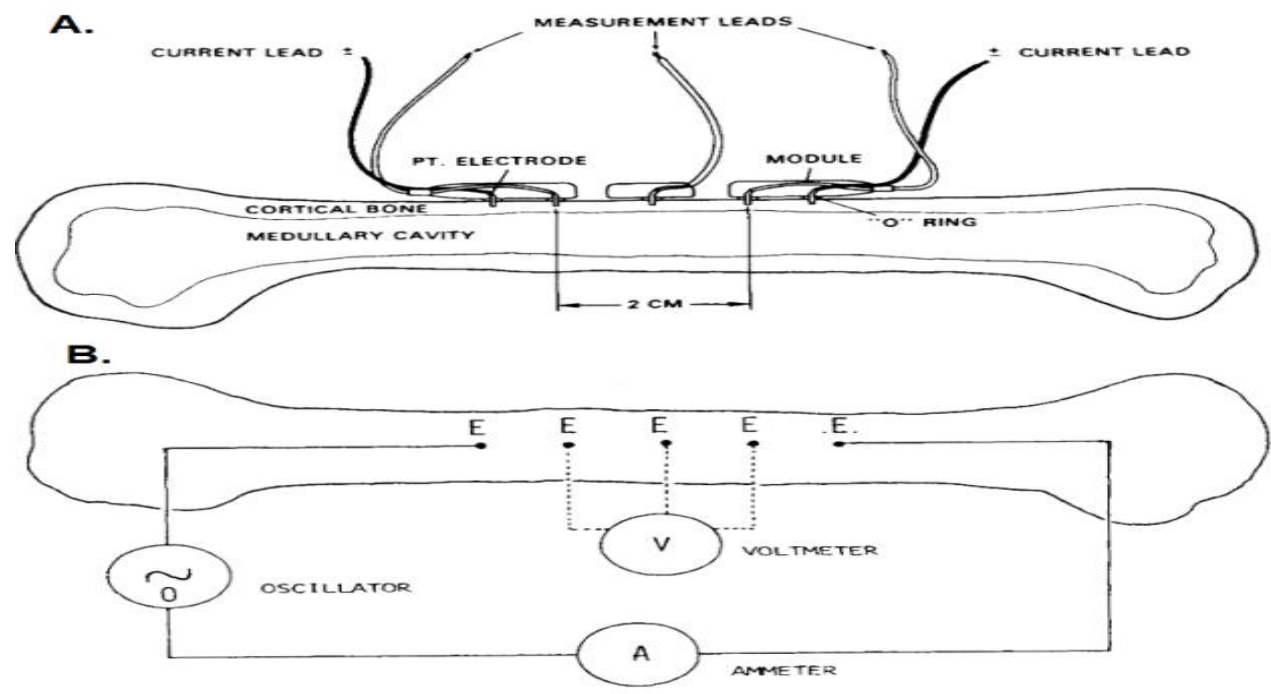

Figure 3. A. Five bone-electrodes affixed onto rabbit femur to measure cortical bioimpedance. B. Circuit diagram with a "current source" to estimate bioimpedance modulus in vivo rabbits. After Rinaldi et al.[46].

2.2.2. Invasive Measurements in Humans. Since long bone fracture reduction is treated with externally exposed nails, some authors have published BIA as healing monitoring evidence $[48,49]$. There is no intention here to detect a fracture, but rather a quantification of a biological process. The nails used for external fixation, are used as "invasive electrodes".

With such settings, Gupta [49] and Kumaravel [48] suggest that bioimpedance measurements could replace $\mathrm{X}$ ray images to determine when the bone healing ends, thus avoiding the use of ionizing radiation. They also speculate on the usefulness of BIA in case of bone union failures or delays. Frequency of $100 \mathrm{~Hz}$ was used along with a LCR-Q meter [49] while Kuramarel [48] used direct current (DC) with 0.1 to 1.0 volts variable tension, using a Scientech ${ }^{\circledR}$ Model ST4073 voltage generator and an ammeter from EIC Meters Private Limited, Bangalore - 560062, India.

It should be noted in passing that neither research group apparently took care of patient safety, as tensions (not currents) were applied to the electrodes and because the frequency used fell within risky ranges according to standards [37].

2.2.3. Non Invasive Measurements in Humans. In the 1980's two British groups, one in Sheffield (England) the other in Aberdeen (Scotland) publish Electrical Impedance Tomography (EIT) applications for extremities [50,51]. Within two years, the Sheffield data collection [52] and the Aberdeen Impedance Imaging system [53] are able to produce transversal 2D images from EIT data collected around the skin.

Aberdeen University publishes EIT applications to produce diagnostics and monitoring evidence of human extremities bone lesions: femur [54], humerus [55,56], tibia [54,55] and peroneum [54]. Volunteers offered both intact and fractured extremities at the bones mentioned. In all cases did the authors use their original equipment and methods [53] with $1 \mathrm{~mA}$ and $10 \mathrm{kHz}$ current successively 
injected in two out of sixteen skin electrodes to measure voltage from the remaining electrode adjacent pairs.

The Kulkarni group (Aberdeen, Scotland) is generally considered in EIT descriptions [4] as well as reviews [57-59] as the developer of bone fracture applications.

As a test for a new multifrequency broadband equipment [60], an EIT reconstructed human upper extremity section was published [61], but with no apparent clinical consequences in later available literature.

Ohmine et al. [62] perform skin electrode measurements on human arms to validate a model. By doing so, they obtain the conductivity of bone as well as other living tissues. There is no attempt here to characterize bone fracture, but it is interesting to mention the fact that they apply a step current to evaluate bioimpedance spectroscopy. Signal analysis theory is employed to obtain the same result as when using classical EIS frequency scanning, but with only one signal [63].

Steihaug et al. [64] use traditional BIA for hip fracture and hip replacement surgery characterization with $50 \mathrm{kHz}$ current at $425 \mu \mathrm{A}$ and tetrapolar array (RJL quantum systems III, RJL systems, USA) and a very similar $50 \mathrm{kHz}$ current at $400 \mu \mathrm{A}$ (Body impedance analyzer BIA $101 \mathrm{ASE}$, Akern Srl, Italy). Measurements are taken on affected side as well as contralateral to show differences in fractured and recently operated patients.

\section{Discussion}

The present revision contains a corpus of knowledge to base upon the development of a method to detect bone fractures using bioimpedance. All ex vivo papers specify the conditions ( $\mathrm{pH}$, direction of measurement, temperature, among others) in which the bioimpedance differences were recorded. This ensures reproducibility. The bioimpedance difference is associated with bone structure discontinuity provided there is a standard to compare it to, e.g. contralateral or further along the bone. The usefulness of the available information encompasses EIT, EIS and BIA alike.

Surprisingly, EIT, and not EIS nor BIA, is the only modality to have been used to attempt to characterize bone lesions. But deciding on whether a long bone is fractured based on low resolution sections is difficult and this is why the result has been poor due to date in terms of clinical use. New mathematical tools available after a quarter of a century [65] and increased computational power are available to allow big steps to be taken in the direction of giving reliable EIT images.

Electrical safety has not always been included in the design of experimental set-ups. This aspect must be addressed if bioimpedance is to be used as some substitute for X ray, i.e. broadly and commonly. Accepted safety standards [37] suggest to use frequencies above $10 \mathrm{kHz}$ and to apply controlled current only, since prevalent voltage on unknown impedances may result in such currents that cause harm to patients.

The basics of bioimpedance extremities measurements have been described here. The next step is to address the clinical need for an easy, non-ionizing, low cost and portable instrument to detect bone fractures wherever pre hospital care is called to act: e.g. at a car accident, in the snow or on a boat at sea. Careful planning of experiments based on the present revision should help in the direction of a safe bone fracture bioimpedance detector.

In the Table 1 shows a practical information resume of the present work. 
Table 1. Bone integrity by Electrical Impedance Measurements

\begin{tabular}{|c|c|}
\hline Authors & Aim \\
\hline $\begin{array}{l}\text { Hemingway } \\
\text { et al. }[10]\end{array}$ & $\begin{array}{l}\text { Know the distribution of } \\
\text { applied currents over } \\
\text { human body for the study } \\
\text { of diathermy effects. }\end{array}$ \\
\hline $\begin{array}{l}\text { Gabriel et } \\
\text { al. }[14-16]\end{array}$ & $\begin{array}{l}\text { Characterize dielectric } \\
\text { properties of different } \\
\text { biological tissues. }\end{array}$ \\
\hline $\begin{array}{l}\text { Mercato et } \\
\text { al. }[18]\end{array}$ & $\begin{array}{l}\text { Establish a relationship } \\
\text { between the high values } \\
\text { of low-frequency } \\
\text { permittivity, bone tissue }\end{array}$ \\
\hline $\begin{array}{l}\text { Saha et al. } \\
{[20,21]}\end{array}$ & $\begin{array}{l}\text { Electrical and dielectric } \\
\text { properties of wet human } \\
\text { cancellous bone from } \\
\text { distal tibiae }\end{array}$ \\
\hline $\begin{array}{l}\text { Arpaia et } \\
\text { al. }[38]\end{array}$ & $\begin{array}{l}\text { EIS measurements the } \\
\text { characterization of the } \\
\text { interface between the } \\
\text { bone and prosthesis. }\end{array}$ \\
\hline $\begin{array}{l}\text { Khan et } \\
\text { al.[39] }\end{array}$ & $\begin{array}{l}\text { Ipedance measurement to } \\
\text { detect bone fracture and } \\
\text { healing monitoring }\end{array}$ \\
\hline $\begin{array}{l}\text { Lin et al. } \\
{[40,41]}\end{array}$ & $\begin{array}{c}\text { EIS to distinguishtissues } \\
\text { involved in bone fracture } \\
\text { repair }\end{array}$ \\
\hline
\end{tabular}

Rinaldi and Measure the conduction Goodrich properties of rabbit femur [46] with five-point method

Yoshida et Bone electrical al. [47] impedance using external fixation pins as electrodes,

Gupta et al. New tool to diagnose [49] non-union of bones.

Kumarevel Can electrical resistance et al. [48] across the fracture be used as a tool to study fracture healing process?

Kulkarni et Generate a new method al. [57-59] to clinical monitoring of bone fracture healing process.

Brown et al. New method for clinical EIT [50] monitoring

Method Signal
Results

Equipment (Model)

BIA $1 \mathrm{MHz}$ High resistance at low Wheatstone bridge frequency is due to $\&$ conductivity cell superficial fat.

(Own

EIS $\quad 10 \mathrm{~Hz}-\quad$ Compendium of

$10 \mathrm{MHz}$ dielectric properties of animal \& human tissues.

BIA $10 \mathrm{~Hz}$, Correlation between the $10 \mathrm{kHz} \&$ low-frequency electric

$1 \mathrm{MHz}$ conductivity and relative permittivity.

EIS $10 \mathrm{kHz}-\quad$ The variations in the

$10 \mathrm{MHz}$ electrical properties for longitudina and transverse directions .

EIA $10 \mathrm{~Hz}-65$ capability to detect $\mathrm{t} a$ $\mathrm{kHz}$ (10 to satisfying connective

$100 \mathrm{mV}$ ) tissue, and its thickness

BIA $\quad 50 \mathrm{kHz}$ Electrical impedance of a $(400 \mu \mathrm{A})$ normal bone is less than that of fractured bone

EIS $\quad 20 \mathrm{~Hz}$ - EIS has the feasibility for

$1 \mathrm{MHz}$ detecting fracture callus

$(100 \mathrm{mV}) \quad$ composition, $\mathrm{h}$

EIS $20 \mathrm{~Hz}-7$ Present bioimpedance

$\mathrm{kHz}(0.1$ values of different parts

to $1.2 \mathrm{~V}$ ) of rabbits femur.

BIA $2 \mathrm{~Hz}(30 \quad$ The bone remodelling $\mu \mathrm{A})$ resulted in an increase of $\mathrm{Z}$ values post healing.

BIA $\quad 100 \mathrm{~Hz} \quad$ Electrical properties as marker for fracture.

BIA DC (0.1 to Resistance versus day

$1.0 \mathrm{~V})$ graph to predict healing.

EIT

$10 \mathrm{kHz}$ Reconstruct the image of

$(1 \mathrm{~mA}) \quad$ a cross section of different human limbs.

$50 \mathrm{kHz}$

(1 mA) developments)

Impedance

(HP4182A)

Impedance

Analyzer

(HP4192A)

Miliohm Meter

(HP4275A)

Impedance

Analyzer

(Solartron 1250 \&

Solartron 1286)

Datalogger

(BIOPAC system

w MP 45 ADunit)

Precision LCR

device (Keysight

E4980AL)

Oscillator

(GR1316) \&

Multimeters

(Keithley 168 \&

Dynasmac 290)

AC electrical stim

BS-1000) Biol.

Amp. \& Oscil

(Kenw DCS8300)

LCR-Q Meter (No information)

V Gen. (Scientech ST4073) \&

Ammeter (EIC

Meters 560062)

Aberdeen

Impedance

Imaging System

Own development

Sheffield Mark 1

(Own

development) Analyzer
Image of a cross section of different human body parts 
Riu et al. Multifrequency

$[60,61]$ measurements in EIT

Steihaug et BIA measurements of hipBIA al. [64] fracture \& repair
EIT $\quad 64 \mathrm{kHz} \&$ Reconstruct the image of

$125 \mathrm{KHz}$ a cross section of a human thigh.

$50 \mathrm{kHz} \quad$ Resistance was lower on $(425 \mu \mathrm{A})$ the side of the fractured $\mathrm{h}$ $\& 50 \mathrm{kHz}$ $(400 \mu \mathrm{A})$
(Own

development)

Bioimpedance

Analyzer (RJL \&

Body Impedance Anal BIA 101ASE

\section{References}

[1] Morucci J P, Valentinuzzi M, Riguad B and Felice C J 1996 Critical reviews in biomedical engineering vol 24 issues 4-6

[2] Ohm G S 1827 Die galvanische kette, mathematisch bearbeitet (Berlin: Kessinger Publishing)

[3] Grimnes S and Martinsen Ø 2014 Bioimpedance and bioelectricity basics (Oslo, Noruega: Academic Publics)

[4] Holder D 2005 Electrical impedance tomography: methods, history, and applications (Institute of Physics Pub)

[5] Dell'Osa A H 2015 Tomografía por impedancia eléctrica : breve revisión Proc. Congr. Soc. Argentina Bioingeniería XX 8

[6] Simini F, Santos E and Arregui M 2017 Electrical impedance tomography to detect trends in pulmonary oedema Bioimpedance in Biomedical Applications and Research ed F Simini and P Bertemes-Filho (Springer International Publishing) pp 45-64

[7] Calderón A P 1980 On an inverse boundary value problem Seminary on Numerical Analysis and its Applications to Continuum Physics (Sociedade Brasileira de Matematica) 65-73

[8] Robbins, Cotran R S, Kumar V and T. C 2000 Patologia estructural y funcional (España: Interamericana)

[9] McRae R 2010 Tratamiento práctico de fracturas (Barcelona, España: Elsevier Health Sciences Spain)

[10] Hemingway A and McClendon J F 1932 The high frequency resistance of human tissue Am. J. Physiol. 102 56-9

[11] Burger H C and Milaan J B 1943 Measurements of the specific resistance of the human body to direct current Acta Med. Scand. 114 584-607

[12] Burger H C and Dongen R van 1961 Specific electric Resistance of Body Tissues Phys. Med. Biol. 5304

[13] Geddes L A and Baker L E 1967 The specific resistance of biological material-a compendium of data for the biomedical engineer and physiologist Med. Biol. Eng. 5 271-93

[14] Gabriel C, Gabriel S and Corthout E 1996 The dielectric properties of biological tissues: I literature survey Phys. Med. Biol. 41 2231-49

[15] Gabriel S, Lau R W and Gabriel C 1996 The dielectric properties of biological tissues: II measurements in the frequency range $10 \mathrm{~Hz}$ to $20 \mathrm{GHz}$ Phys. Med. Biol. 41 2251-69

[16] Gabriel S, Lau R W and Gabriel C 1996 The dielectric properties of biological tissues: III parametric models for the dielectric spectrum of tissues Phys. Med. Biol. 41 2271-93

[17] Gabriel C, Chan T Y A and Grant E H 1994 Admittance models for open ended coaxial probes and their place in dielectric spectroscopy Phys. Med. Biol. 39 2183-200

[18] De Mercato G and Garcia Sanchez F J 1992 Correlation between low-frequency electric conductivity and permittivity in the diaphysis of bovine femoral bone Proc. IEEE Trans. Biomed. Eng. 39 523-6

[19] Casas R and Sevostianov I 2013 Electrical resistivity of cortical bone: micromechanical modeling and experimental verification Int. J. Eng. Sci. 62 106-12

[20] Saha S and Williams P A 1995 Comparison of the electrical and dielectric behavior of wet human cortical and cancellous bone tissue from the distal tibia J. Orthop. Res. 13 524-32

[21] Saha S and Williams P A 1989 Electric and dielectric properties of wet human cancellous bone 
as a function of frequency Ann. Biomed. Eng. 17 143-58

[22] Saha S and Williams P A 1988 Effect of various storage methods on the dielectric properties of compact bone Med. Biol. Eng. Comput. 26 199-202

[23] Saha S, Reddy G N and Albright J A 1984 Factors affecting the measurement of bone impedance Med. Biol. Eng. Comput. 22 123-9

[24] Balmer T W, Vesztergom S, Broekmann P, Stahel A and Büchler P 2018 Characterization of the electrical conductivity of bone and its correlation to osseous structure Sci. Rep-UK. 8 8601

[25] Singh S 1987 Electric Properties of wet whole bone J. Bioelectricity 6 169-80

[26] Singh S and Beharl J 1984 Frequency dependence of electrical properties of human bone $J$. Bioelectricity 3 347-56

[27] Durand B, Christel P and Assailly J 1978 In vitro study of electric impedance of bone Electric Stimulation of Bone Growth and Repair (Berlin, Heidelberg: Springer Berlin Heidelberg) pp 19-24

[28] Unal M, Cingoz F, Bagcioglu C, Sozer Y and Akkus O 2018 Interrelationships between electrical, mechanical and hydration properties of cortical bone J. Mech. Behav. Biomed. 77 $12-23$

[29] Sierpowska J, T yr s J, Hakulinen M A, Saarakkala S, Jurvelin J S and Lappalainen R 2003 Electrical and dielectric properties of bovine trabecular bone relationships with mechanical properties and mineral density Phys. Med. Biol. 48 775-86

[30] Sierpowska J, Hakulinen M A, Töyräs J, Day J S, Weinans H, Kiviranta I, Jurvelin J S and Lappalainen R 2006 Interrelationships between electrical properties and microstructure of human trabecular bone Phys. Med. Biol. 51 5289-303

[31] Sierpowska J 2007 Electrical and dielectric characterization of trabecular bone quality (University of Kuopio)

[32] Ciuchi I V, Curecheriu L P, Ciomaga C E and Sandu A V 2010 Impedance spectroscopy characterization of bone tissues J. Adv. Res. Phys. 1 1-5

[33] Sierpowska J, Lammi M J, Hakulinen M A, Jurvelin J S, Lappalainen R and Töyräs J 2007 Effect of human trabecular bone composition on its electrical properties Med. Eng. Phys. 29 $845-52$

[34] Singh S and Saha S 1984 Electrical properties of bone. A review. Clin. Orthop. Relat. R. 186 249-71

[35] Kosterich J D, Foster K R and Pollack S R 1983 Dielectric permittivity and electrical conductivity of fluid saturated bone IEEE Trans. Biomed. Eng. 30 81-6

[36] Schaur S, Jakoby B and Kronreif G 2012 Position-dependent characterization of bone tissue with electrical impedance spectroscopy IEEE Sensors 1-4

[37] International Organization for Standardization 2015 IEC 60601 (Geneva, Switzerland)

[38] Arpaia P, Clemente F and Zanesco A 2007 Low-invasive diagnosis of metallic prosthesis osseointegration by electrical impedance spectroscopy IEEE Trans. Instr. Meas. $\mathbf{5 6}$ 784-9

[39] Khan M, Sirdeshmukh S P S M A and Javed K 2016 Evaluation of bone fracture in animal model using bio-electrical impedance analysis Perspect. Sci. 8 567-9

[40] Lin M C, Yang F, Herfat S T, Bahney C S, Marmor M and Maharbiz M M 2017 New opportunities for fracture healing detection: impedance spectroscopy measurements correlate to tissue composition in fractures J. Orthop. Res. $352620-9$

[41] Lin M C, Herfat S T, Bahney C S, Marmor M and Maharbiz M M 2015 Impedance spectroscopy to monitor fracture healing Conf. Proc. IEEE. Eng. Med. Biol. Soc. 5138-41

[42] Friedenberg Z B and Brighton C T 1966 Bioelectric potentials in bone J. Bone Joint Surg. Am. 48 915-23

[43] Bassett C A and Becker R O 1962 Generation of electric potentials by bone in response to mechanical stress Science 137 1063-4

[44] Bassett C A, Pawluk R J and Becker R O 1964 Effects of electric currents on bone in vivo. 
Nature 204 652-4

[45] Becker R O, Spadaro J A and Marino A A 1977 Clinical experiences with low intensity direct current stimulation of bone growth Clin. Orthop. Relat. Res. 75-83

[46] Rinaldi R A and Goodrich J D 1982 Bone electrical conduction J. Bioelectricity 1 83-97

[47] Yoshida T, Kim W-C, Kawamoto K, Hirashima T, Oka Y and Kubo T 2009 Measurement of bone electrical impedance in fracture healing J. Orthop. Sci. 14 320-9

[48] Kumaravel S and Sundaram S 2012 Monitoring of fracture healing by electrical conduction: a new diagnostic procedure Indian J. Orthop. 46384

[49] Gupta K, Gupta P, Singh G, Kumar S, Singh R and Srivastava R 2013 Change in electrical properties of bone as diagnostic tool for measurement of fracture healing Hard Tissue 2

[50] Brown B H, Barber D C and Seagar A D 1985 Applied potential tomography: possible clinical applications Clin. Phys. Physiol. Meas. 6 109-21

[51] Ritchie I K, Chesney R B, Gibson P, Kulkarni V and Hutchison J M 1989 Impedance osteography: a technique to study the electrical characteristics of fracture healing Biomed. Sci. Instrum. 25 59-77

[52] Brown B H and Seagar A D 1987 The Sheffield data collection system Clin. Phys. Physiol. Meas. 8 91-7

[53] Kulkarni V, Hutchison J M and Mallard J R 1989 The Aberdeen Impedance Imaging System Biomed. Sci. Instrum. 25 47-58

[54] Ritchie I K and Kulkarni V 1990 Impedance osteography: clinical applications of a new method of imaging fractures J. Biomed. Eng. 12 369-74

[55] Kulkarni V, Hutchison J M S, Ritchie I K and Mallard J R 1990 Impedance imaging in upper arm fractures J. Biomed. Eng. 12 219-27

[56] Kulkarni V, Hutchinson J M S, Ritchie I K, Chesney R B, Gibson P and Mallard J R 1989 Monitoring fracture healing by impedance imaging Proc. Ann. Int. Eng. Med. Biol. Soc. 4789

[57] Dijkstra A M, Brown B H, Leathard A D, Harris N D, Barber D C and Edbrooke D L 1993 Review clinical applications of electrical impedance tomography J. Med. Eng. Technol. 17 89-98

[58] Jongschaap H C, Wytch R, Hutchison J M and Kulkarni V 1994 Electrical impedance tomography: a review of current literature Eur. J. Radiol. 18 165-74

[59] Kotre C J 1997 Electrical impedance tomography Br. J. Radiol. 70 200-5

[60] Riu P, Rosell J and Pallas-Areny R 1992 In vivo static imaging for the real and the reactive parts in electrical impedance tomography using multifrequency techniques Proc. Ann. Int. Conf. IEEE Eng. Med.and Biol. Soc. 1706-7

[61] Riu P J, Rosell J, Lozano A and Pallàs-Areny R 1992 A broadband system for multifrequency static imaging in electrical impedance tomography Clin. Phys. Physiol. Meas. 13 61-5

[62] Ohmine Y, Morimoto T, Kinouchi Y, Iritani T, Takeuchi M, Haku M and Nishitani H 2004 Basic study of new diagnostic modality according to non-invasive measurement of the electrical conductivity of tissues $J$. Med. Invest. $51218-25$

[63] Pueyo H and Marco C 1985 Analisis de modelos circuitales I (Buenos Aires, Argentina: Arbó)

[64] Steihaug O M, Bogen B, Kristoffersen M H and Ranhoff A H 2017 Bones, blood and steel: how bioelectrical impedance analysis is affected by hip fracture and surgical implants J. Electr. Bioimp. 8 54-9

[65] Alberti G S and Santacesaria M 2018 Calderon's inverse problem with a finite number of measurements (Preprint arXiv:1803.04224) 